\title{
Entrevista com Diana Tussie: a economia política internacional latino-americana, visões de uma fundadora
}

\author{
Aline Contti Castro ${ }^{1}$ \\ Juliana Peixoto Batista ${ }^{2}$
}

DOI: 10.5752/P.1809-6182.2020v17n2p67

Recebido em: 14 de abril de 2020

Aceito em: 11 de maio de 2020

A Profa. Diana Tussie é Coordenadora da área de Relaçôes Internacionais da Flacso-Argentina e é uma das mais destacadas intelectuais latino-americanas na área de Economia Política Internacional (EPI). Doutorou-se na London School of Economics, onde envolveu-se no grupo de pesquisa da renomada Susan Strange, ícone da EPI. Foi premiada pela ISA (International Studies Association) em 2017, reconhecida como "Distinguished Global South Scholar", além de outros prêmios como "Distinguished Fulbright Scholar in International Relations" no 50a Aniversário da Comissão Fulbright. Exerceu funçôes no governo argentino, atuando na área de negociaçôes econômicas internacionais. Publicou dezenas de livros e artigos científicos.

Nessa entrevista, ela fala de sua trajetória profissional, de sua relação com Susan Strange e analisa o campo da EPI na América Latina. Além disso, aborda temas como as relações entre teoria e prática, as relações Brasil-Argentina, a hegemonia brasileira e o regionalismo latino-americano.

\section{Após sua Licenciatura em} Sociologia na Universidade de Buenos Aires (UBA), você realizou seus estudos de Mestrado e Doutorado na Inglaterra, onde participou do grupo de pesquisa de Susan Strange. Quais foram suas principais impressões dessa experiência? Havia elementos de convergência entre a leitura da sociologia/economia política da América Latina e a produzida na Inglaterra naquele momento?

É muito interessante poder refletir com vocês, é interessante poder juntar a conjuntura histórica com a história pessoal (porque esta se insere no momento histórico, mais amplamente). Cheguei à Inglaterra em 1976, ano do golpe na Argentina. Eu estava muito órfã de

\footnotetext{
1 Coordenadora do Curso de Graduação em RelaçõesInternacionais e Professora do Programa de Pós- Graduação em Gestão Pública e Cooperação Internacional (PGPCI) da Universidade Federal da Paraíba (UFPB). Doutora em Relaçóes Internacionais pela Universidade de Brasília (IREL-UnB) em parceria com o Instituto Superior de Ciências Sociais e Políticas da Universidade de Lisboa (ISCSP-UL). ORCID: https://orcid.org/0000-0002-3595-2445. Contato: alinec.ufpb@gmail.com.

2 Doutora em Direito, com especialização em Direito Internacional (UBA, Argentina). Mestra em Relaçóes Internacionais (UBA, Argentina). Docente na UBA, UNSAM y FLACSO. ORCID: http://orcid.org/0000-0003-0341-5909. Contato: jpeixoto@flacso.org.ar.
} 
projeto, não sabia o que fazer, tinha uma filha recém-nascida. Não quero dizer que era difícil porque muitas pessoas passaram situaçóes muito piores, mas para mim foi um momento de orfandade. Eu vinha, obviamente, das lutas estudantis da década de 1970 em toda a América Latina (e também na Argentina) e, um pouco ingenuamente, quis estudar o imperialismo. Também porque já que estava na Inglaterra, fazia sentido estudar as açóes do imperialismo. E, assim, eu decidi estudar Relaçôes Internacionais, para ver como os países se projetam internacionalmente. Era um pouco ingênuo como eu pensei naquele momento.

E praticamente não havia a área de estudos de Relaçóes Internacionais na América Latina naquela época...

Não. A disciplina de Relaçôes Internacionais é muito nova. A grande disciplina, na América Latina, era a Sociologia. Em grande parte, a Sociologia é a mãe de nossa disciplina em Ciências Sociais (exceto Economia). Mas, para dar um indicador, a Associação Latino-Americana de Sociologia foi fundada em 1950. A Sociologia estava muito internacionalizada, com os pais da Sociologia na América Latina, na Colômbia, no Brasil, na Argentina, no México, no Chile, além do papel da Cepal e da Flacso no Chile. A Sociologia foi uma grande integradora.

Voltando à minha chegada na Inglaterra, eu não queria perder tempo, então decidi estudar o imperialismo. Susan não era minha orientadora imediata e me designaram outro Professor orientador, mas eu estava muito próxima das pesquisas que ela fazia, e ela tinha um seminário de pesquisa de doutorandos/as em que nós participávamos muito. Tínhamos uma relação muito próxima, ela era uma pessoa muito afetiva, integrava muito as pessoas, era muito carismática. Então, em algum momento, minha tese, como todas as teses, não avançava. Ela queria que todos terminassem, ela pegou minha tese, leu e me impulsionou a terminar de alguma maneira, me empurrando para fazer a defesa.

Sobre o tema de como eu via esse momento, os anos de 1970 eram um período de muita ideologização, digamos. Então, no grupo de pesquisa, nos aproximávamos de Susan porque ela era uma pessoa muito carismática e muito eclética. Ela dizia que tínhamos que compor a Economia Política Internacional como um minestrone, uma sopa. A briga dela era com os economistas e com a "securocracia" das Relaçôes Internacionais. Todo o resto, que não fosse uma dessas coisas, lhe interessava, compunha a sopa que ela estava montando que era muito interessante.

Mas nós, como estudantes, a víamos como muito eclética e pouco marxista (risos), pouco identificada com uma corrente teórica específica. Era muito difícil classificá-lo, o que incomodava alguns. Eu tive menos problemas com isso porque não vinha do marxismo. Mas achava difícil e ficava incômoda com a falta de perspectiva sobre os países em desenvolvimento. Lembro-me claramente de perceber isso, que ela não olhava a inserção dos países em desenvolvimento, o Sul não existia. Ela dizia, naquele momento, que a EPI era o que os países poderosos faziam, ela tinha isso praticamente definido. Havia países em desenvolvimento, mas eles não influenciavam o sistema internacional. Então eu tinha essa diferença com ela, porque eu queria estudar isso, os países em desenvolvimento. Todos os que estavam voltados a essa discussão tinham desconforto. Susan não era uma pessoa rígida, então não havia problema, mas havia sim uma espécie de discussão, de debate com ela. Não havia o diálogo com os 
temas relativos ao desenvolvimento. Para ela, o diálogo era com os economistas mainstream e com as Relações Internacionais mainstream.

Hoje vejo que isso também fazia parte da rigidez de nós, jovens. Ela tinha uma grande simpatia por tudo o que era "underdog" (menos favorecido) e era feminista de uma forma muito genuína, o que se traduzia em pequenos e grandes atos. Acho que nossa aproximação tinha a ver com o fato de que ela apoiava as mulheres. Além disso, quando finalmente terminei minha tese, ela queria que, na minha banca, estivessem especialistas de países em desenvolvimento e colocou Hans Singer, "irmão" de Prebisch, com quem ele escrevera a tese Prebisch-Singer. Foi fantástico para mim tê-lo. Para mim, naquele momento, era como ter Deus na banca (risos) e foi muito interessante. Ela tinha essa empatia, essa flexibilidade. Eu a via como uma pessoa muito eclética, essa era sua força.

\section{Você voltou para a Argentina no período de redemocratização e foi uma das fundadoras da disciplina de EPI no país. Qual foram os desafios iniciois?}

Primeiro, não me sentia fundadora. Estava formada e havia terminado minha tese sobre o GATT, e era um momento em que o GATT/OMC começava a ser muito relevante, então meus trabalhos foram muito demandados. Meu primeiro livro sobre o GATT (de 1987-88) saiu bem no momento da Rodada Uruguai. Foi um livro muito lido, mas náo me sentia fundadora de nada. Eu sentia que tinha um nicho que era a Economia Política. Eu não era economista, mas já a esta altura eu sabia muito de Economia, eu era quase uma economista de alguma forma, muitos pensavam que eu era economista (risos).
Meu livro era uma referência. Ademais, começava a se notar muito fortemente que as Relaçôes Internacionais na América Latina estavam ligadas, por um lado, com a abertura que os países estavam fazendo e, por outro lado, com a crise da dívida que havia comprometido recursos e que, ao mesmo tempo, demandava o diálogo com o Banco Mundial e o Fundo Monetário Internacional. Tudo coincidia nessa mesma época. E de repente, minhas áreas de pesquisa viraram os temas da moda (foi aí que eu comecei). Eu sentia que havia um espaço e que havia muita demanda.

Além disso, nessa época, sentia que me interessava a política pública, quase mais do que a academia nesse momento. De fato, estive trabalhando no governo de [Raúl] Alfonsín [Presidente da Argentina entre 1983-1989] e foi muito interessante. Eu gostava de estar nas negociaçóes, aprendi muito, lia os contratos, o que havia que negociar, entáo me encantava a parte das políticas públicas.

\section{Você tormbém traboulhou em} cargos executivos na Argentina no período 2000-01*, em um momento muito crítico da história nacional. Que reflexões far sobre esse trabalho - em especial em relação à interface entre o mundo acadêmico e o político? (Há muitas diferenças entre a teoria e a prática?)

*(Tussie participou da Comissão Nacional de Comércio Exterior e foi Subsecretória de Negociações Econômicas Internacionais)

Eu não venho da teoria, Susan Strange tampouco, é preciso ter isso em mente. Em certo sentido, eu me modelei nela. O que sou, construtivista, idealista, realista? Esse debate... Não sou nada, eu quero saber como é o mundo. 
E para saber como é o mundo, não preciso ter uma ideologia. É importante o compromisso com a mudança, o compromisso com o desenvolvimento, o compromisso social, mas não esse debate infrutífero de hoje... Se nós estamos obrigando os estudantes a chegar à prática por meio da teoria, lhes estamos fazendo muito mal (risos). É necessário fazer uma pergunta: como funciona? Portanto, como se ordena, quais são as regras? E não como se está fazendo agora. As teorias são explicaçôes ideológicas da realidade, elas me servem ou não. Muitas me servem, outras não. Além disso, essas teorias, nas quais os estudantes latino-americanos de Relaçôes Internacionais estão sendo educados, são teorias importadas.

Por isso acho que Susan [Strange] foi muito importante, porque ela ampliou minha visão. Ela nos permitia liberarmos disso e primava pela construção de uma perspectiva eclética, ainda que eu não percebesse a importância disso naquele momento. Ela queria mudar o mundo e náo se preocupava (com os rótulos). Eu acho que isso me permitiu uma liberdade intelectual, para além das minhas críticas naquele momento. Qual é o problema que eu tinha que resolver? O problema da atual geração ao começar a trabalhar com políticas públicas é justamente este, de começar pela teoria. Bem, o que eu faço com o Estado? (risos) Essa pergunta é muito grande. Eu deveria perguntar o que faço com essa política, não o que faço com o Estado.

Obviamente, quando tenho que escrever um trabalho acadêmico é outra coisa...

As teorias são fatos sociais, não são a Bíblia, não são uma religião. Elas são produzidas por pessoas e geralmente homens do norte, brancos. Náo podemos nos comprometer a olhar a realidade através de seus óculos.

\section{Entáo sua experiência no governo (na Se-} cretaria de Comércio) contribuiu para que, posteriormente, você fizesse análises acadêmicas...

Sim, muito. Para mim, foi a experiência mais linda que tive. Primeiro, porque é muito interessante observar o que você estuda e perceber como isso funciona, como funcionam os lobbies, como te compram, como não te compram, como sabem que a mim não compram, como sabem que podem vender determinado produto a um governo, mas que náo podem vender outro. Falando em lobbies e negociaçôes internacionais, também é muito interessante ver como o poder se desdobra, o poder simbólico se desdobra, quando alguém pega o telefone e lhe dá uma ordem, o Ministro ou alguém de outro país com alguma necessidade específica.

\section{Quais as principais semelhanças e diferenças relativas à renegociação da dívida argentina de 2001 e de hoje?}

A dívida é, para a América Latina, exceto o Chile, uma condição estrutural desde as guerras de independência. É o fator que condiciona os países, podendo limitar por um lado ou, por outro, oferecer a possibilidade de uma maior margem de endividamento - evitando algum ajuste por meio de novos empréstimos etc. A dívida está sempre presente, desde 1820, em todos os países da América Latina e da África...

O caso da Ásia já é diferente, teve outros problemas. A partir de 1945, Taiwan e Coréia tiveram um apoio financeiro muito importante que evitou que recorressem ao Fundo Monetário Internacional - sendo que eles tinham um déficit na balança comercial...

$\mathrm{Na}$ América Latina, a dívida foi muito relevante e deve-se levar em consideração que o 
Fundo Monetário Internacional realizou seu primeiro empréstimo de ajuste ao Peru em 1952. A América Latina foi quase um laboratório para a atuação do Fundo, em relação a como eles iriam fazer o ajuste quando um país apresentava déficit na balança comercial. Portanto, a dívida é uma questão permanente. Em minhas pesquisas, meu foco maior foram as instituições - o FMI, o Banco Mundial, o BID - no tocante à sua composição e motivaçóes políticas.

A relação com o Fundo é muito importante, como estamos vendo agora na Argentina e no Equador, e podemos contrastar com o Chile, que nunca teve um problema com o Fundo desde Pinochet. Na década de 1980, todos os países da América Latina tiveram problemas com o Fundo, mas o Chile náo porque se ajustou e pagou a dívida. Os demais países tentaram proteger sua população - não conseguiram - e contraíram novos empréstimos. O Chile cancelou a dívida e temos o resultado que temos hoje.

Hoje a grande diferença é que o FMI não está obrigatoriamente em apoio dos grandes Fundos que participam das negociaçóes com a Argentina. O FMI está pedindo aos credores que reduzam a dívida, que percam. Em outras crises, o Fundo saia para resgatar os credores. Agora estão dizendo a eles para arcarem com os seus prejuízos.

\section{A Argentina viveu uma trajetória de piora dos indicadores sociais nas últimas décadas, culminando na grave crise atual. Que fatores sistêmicos explicam a atual crise econômica e social?}

Não sei se são fatores sistêmicos... A América Latina não fez reformas impositivas para que não tenhamos esses megamilionários. É claro que o sistema internacional é permissivo, está claro nos Panamá Papers etc. Mas nós não fizemos nada para reformar nossos países, há uma questão de pouco compromisso social em nossos países.

Então pensa que os fatores internos são mais relevantes...

Claro, nós convivemos com a pobreza como algo natural, como se fosse uma coisa que não se pode mudar. Nas palavras de Nora Lustig, não há uma "aversão à pobreza".

6. Nos últimos anos, se fortaleceu na Argentina uma visão crítica sobre a atuação regional brasileira, que estaria voltada à construção de uma hegemonia. Em que fatores se fundomentom essa leitura e qual a sua perspectiva?

Vocês no Brasil, de forma semelhante aos norte-americanos, lhes custa entender que há hegemonia. Voltando atrás a Susan Strange, foi muito interessante como ela visualizou a hegemonia norte-americana. Eles reclamavam, nos anos de 1970, a tese do declínio da hegemonia, como se os Estados Unidos tivessem perdido poder. Susan contradizia isso. Chamo a mesma atenção para o Brasil. Vocês brasileiros devem entender a tese da hegemonia brasileira. É muito importante sair do seu próprio centro, descentralizar a perspectiva. Posso te dar indicadores de hegemonia. O Brasil definiu as posiçóes da Tarifa Externa Comum (TEC) no Mercosul, internacionalizou o BNDES, armou a Unasul...

\section{É importante pensar o Brasil desde esse lugar,} de hegemonia regional. Podemos ter uma visão benevolente dessa hegemonia, não quero culpar o Brasil, muito pelo contrário. Muitas vezes, durante a época de fundação do Mercosul, aqui dizíamos que, se não fosse o Brasil, teria havido uma abertura muito mais radical, 
o Brasil nos salvou (risos). É por isso que é hegemonia, essa hegemonia nos serviu, por isso não é necessariamente ruim. Estar neste carro onde o outro me ajuda é bom. Em termos mais amplos, históricos, podemos dizer que muito poucas coisas puderam ser feitas na América do Sul sem incluir o Brasil. Embora, hoje em dia, eu não sei como vai ficar isso, vamos ver...

$\mathrm{Na}$ área de segurança, ainda hoje existem muitas disputas dos argentinos com o Brasil sobre a liderança no Conselho de Segurança ...

Muitos reclamam, é claro... Mas é a vida, é o maior país, com mais recursos. Vocês se pensarem como influentes é importantíssimo, e é parte do que vocês têm que fazer como acadêmicos também. Por exemplo, há muito poucos estudos sobre o regionalismo no Brasil, isso demonstra que não estão olhando muito para a hegemonia, chame como quiser. Você pode náo usar o termo hegemonia porque pode ter um tom crítico, mas pode usar influência. $\mathrm{O}$ Brasil é líder, influente na região. Se o país vai liderar a partir da regiáo ou vai trazer o poder do âmbito internacional, desde fora, para a região, é outro debate. Mas pensar a influência é muito importante.

\section{Sobre o regionalismo pós-} hegemônico [termo cunhado pela Profa. Tussie e pela Profa. Pía Riggirozzi], quais são os principais elementos de sua crise atual - em especial da Unasul - e quais as perspectivas de continuidade desse projeto?

Primeiro, temos que falar sobre o regionalismo. Este tem muitos usos. Lembro-me da frase de Fernando Henrique Cardoso que dizia, precisamente, que o regionalismo servia para as negociaçóes na ALCA. Em 1990, para o Brasil, para isso servia o regionalismo. E a Argentina neste momento, liderada por Menem, necessitava da aliança com os Estados Unidos, antes da aliança com o Brasil. Havia uma disputa muito interessante porque Fernando Henrique dizia que não, que aqui era necessário montar um bloco negociador.

Depois, vem a crise de 2001, o que chamamos de regionalismo pós-hegemônico e o surgimento do Brasil como líder, ocorrendo ao mesmo tempo que a ascensão da China e dos BRICS em geral. Aí há outra situação geoeconômica internacional que permite outros jogos, entre eles, é claro, a Unasul. Muitas coisas aconteceram na Unasul, o CDS (Conselho de Defesa Sul-Americano), a iniciativa de uma Nova Arquitetura Financeira Regional (NAFR), o Banco do Sul, que o Brasil não queria firmar, o Tribunal de Investimentos que queria armar [Rafael] Correa [Presidente do Equador entre 2007-2017] etc. A Unasul serviu de guarda-chuva para muitos temas. Como não pode ser de outra forma, o regionalismo ademais segue o vaivém dos modelos de desenvolvimento, se conforma de acordo com o modelo de inserção que têm os países. Se o modelo de inserção muda, o regionalismo vai mudar. Foi o que aconteceu com a Unasul, e também o que aconteceu com o Mercosul. Mudam os modelos de inserção, mudam as prioridades.

No Mercosul, a partir do início do século XXI, a China se transforma em seu quinto sócio, seu parceiro silencioso, se torna o principal destino para as exportaçóes brasileiras e o segundo mercado para os produtos argentinos. Além disso, a China torna-se um concorrente muito importante no mercado argentino, em relaçáo aos produtos brasileiros. Ou seja, começamos a comprar da China mais do que do Brasil. Mesmo sem fazer parte da uniáo aduaneira, são parceiros. Isso leva a uma reconfiguração das forças do Mercosul. 
Entáo todas as mudanças que tivemos nos últimos anos, mudanças econômicas, geoeconômicas, políticas, ideológicas mudam o modelo, vão mudando o regionalismo que precisamos. E isso vai continuar sendo assim...

Sobre a Unasul, você acha que um dos principais elementos da crise foi a divergência entre Brasil e Venezuela (Lula e Chávez)? Vê mais convergência ou divergência entre eles?

Creio que, na realidade, a Unasul serviu para que Lula e Chávez não entrassem em conflito a respeito de quem liderava a América do Sul. O debate era esse, quem liderava. E o Brasil, pela primeira vez, viu sua hegemonia sendo disputada. E se cria a Unasul para construir as convergências, domesticar a [Hugo] Chávez [Presidente da Venezuela entre 1999-2013], para negociar com ele em um entorno mais amistoso, mais cooperativo. A Unasul serviu muito para isso...

\section{No Brasil, desde o início do} século XXI, houve uma mudança politica e semôntica em sua política externa - com uma foco menos latino-americanista e mais ênfase na América do Sul. Acha esta uma mudança interessante (se distanciando do México e da América Central)? Ou acredita que há mais fatores que nos aproximam?

Fernando Henrique armou essa mudança. Percebia que, para o norte, o México estava com os Estados Unidos. A América do Sul, entáo, seria para o Brasil, porque o país poderia controlar essa região (sobre a outra, o Brasil não tinha controle). Fazia parte do projeto de liderança, que continuou com Lula de outra maneira. Houve uma segmentação geoeconômica feita pelo Brasil. Na Argentina, há um debate se concordamos com essa separação da América do Sul em relação à América Latina... O que acontece, mais recentemente, é que o México tem uma ação de voltar à região, se arma o Grupo de Puebla e há outros movimentos.

Nesse sentido, acha que a CELAC pode desempenhar um papel político importante nos próximos anos?

A CELAC é mais um mecanismo de coordenação, então é preciso ver o que vamos demandar. Não será um mecanismo de integração, é um mecanismo de coordenação. $\mathrm{Na}$ história da América Latina, a ideia de concertação é muito forte. A região teve e tem muitos mecanismos de concertação, o Grupo do Rio, o Grupo da Contadora, o mecanismo do consenso de Cartagena para a dívida. A concertação é muito importante como tradição na América Latina, muito intensa (mais que a divisão). O que acontece é que não a estudamos, o que é outra coisa, então dizemos que ela não existe. Não, nós não a estudamos. Além disso, outra coisa que acontece e que é pouco estudada é o GRULAC [Group of Latin American and Caribbean States] e sua atuação em organizaçôes internacionais. Esse tipo de bloco regional não é de negociação, mas sim de coordenação de algumas posiçóes, onde as informaçôes são compartilhadas no âmbito das organizaçóes internacionais, na OMC, nas Naçóes Unidas, etc.

\section{Finalmente, como você vê o avanço da Economia Política Internacional (EPI) na Argentina e na América Latina hoje? Quais os principais desafios para o avanço e fortalecimento dessa órea de estudos na regiõo?}

Eu nunca vejo a metade do copo vazio. É verdade que a EPI não tem uma predominância na área de Relaçóes Internacionais, mas está crescendo como nunca antes. Como falei, não 
me via como fundadora porque me via como marginal. Então quando me chamam de fundadora, percebe-se que algo está acontecendo, que o campo está sendo construído. $\mathrm{O}$ que significa esse campo? Bem, voltemos à ideia de Susan [Strange] do minestrone, da sopa digamos. As coisas se vão juntando aos poucos. A Economia Política na América Latina, como em todos os lugares, inclui pessoas que vêm de áreas diversas, Direito, Economia (talvez um pouco menos), Sociologia, Relaçóes Internacionais, Regionalismo e Integração, Saúde, Meio Ambiente etc. Tem crescido muito nos últimos anos. Então, de repente, se está formando uma identidade que não havia. Qual é essa identidade? É necessário pensá-la. Nós nos reconhecemos como formando um campo de estudos, com muitas teorias-fatos sociais (não explicações do mundo). Nesse momento, está convergindo a consciência de que nós, dentro do campo, temos ação.

Antes se pensava, por exemplo, que os países em desenvolvimento não marcavam a agenda, não influenciavam. Para o realismo estrutural e para o marxismo, o determinismo era muito forte.

$\mathrm{O}$ que veio acontecendo por meio do construtivismo e de enfoques neogramscianos em temas como o regionalismo, e depois em muitos outros temas, é que percebemos que podemos agir. Posso retirar essa tarifa ou posso pedir a tal país que não faça isso. A Bolívia pode me pedir para aumentar o preço da energia, por exemplo. Isso mostra ação e terá "entitlement" (prerrogativa jurídica). Então há algo que acontece a partir dos anos de 1990 em diante, desde o Regionalismo, que nos permitiu ver que nós temos ação. Não somente temos estrutura, há agência. Eu posso mudar o mundo, não tenho que esperar a revolução chegar. Se vier a revolução, está bem (risos). Mas, enquanto isso, também se pode fazer coisas. Isso é que a EPI nos está apontando. Nós olhamos para a estrutura, olhamos o que há. Há ação, e se está estudando essa ação. Quem são os que atuam? Como se atua? Onde se atua? Como se muda? Isso é muito interessante. Não estamos, primeiro, na inação do determinismo, nem esperando a revolução de $2100 \ldots$ Não, é aqui. Por exemplo, quero saber como funciona o Fundo porque lhe peço tal coisa, essa outra não lhe posso pedir. Quero saber como funcionam os empréstimos do Banco Mundial... Assim, estudamos "what makes the world go round" [o que move o mundo]. Isso está acontecendo. Sigamos adiante.

Buenos Aires, 25/10/2019. 